\title{
Drug Utilization Evaluation Of Antihypertensives In A Tertiary Care Teaching Hospital.
}

\author{
Dr Baharul Islam $\mathbf{H}^{1 *}$, Dr Amirhossein Abedini ${ }^{1}$, Dr Suvijin $\mathrm{C}^{1}$, Dr Shinad AV ${ }^{1}$, Shaeena MH ${ }^{2}$, \\ Dr Mohan Kumar $G^{2}$, Dr Rajesh Venkataraman ${ }^{2}$ \\ ${ }^{1}$ Farooqia College of Pharmacy, Mysore, RGUHS, Karnataka, India \\ ${ }^{1}$ Department of Clinical Pharmacy, CSI Holdsworth Memorial Hospital, Mysore, Karnataka, India \\ ${ }^{2}$ Department of Medicine CSI Holdsworth Memorial Hospital, Mysore, Karnataka, India \\ ${ }^{2}$ Department of Pharmacy Practice Adichunchanagiri college of pharmacy, ACU, Mandya,Karnataka, \\ India
}

\section{*Corresponding Author:}

Dr Baharul Islam H, Assistant professor, Department of Pharmacy Practice

Farooqia College Of Pharmacy,Mysore,India

Email: dr.islambaharul@gmail.com

\begin{abstract}
INTRODUCTION: A study on antihypertensive usage in a tertiary care teaching hospital necessary to realize that drugs inappropriate use represents a potential hazard to the patient and unnecessary expenses. This necessitates a periodic review of the pattern of drug utilization to ensure safe and effective treatment. The ultimate goal is to focus on the factors related to the prescribing, dispensing, administering and taking medication.
\end{abstract}

AIM: To analyse the drug utilization evaluation of antihypertensives in a tertiary care teaching hospital.

METHODOLOGY: A prospective, observational and analytical study was carried out for six months from November 2019 to April 2020 in the inpatient from different departments of a tertiary care teaching hospital in Mysore district with the aim of drug utilization evaluation antihypertensives.

RESULT: A total of 332 patients were taken into the study. 32\% (103) of the patient were in the age group of 41-50 years, and this was found to be higher in a male population, $57 \%$. During the study, $51.6 \%$ of the patients were stage 1 hypertension, followed by prehypertension and stage 2 hypertension. The most common class of drugs prescribed in the study was ACE inhibitors, $31.1 \%$, followed by CCB $21.4 \%$, and the most prescribed medication in the study were captopril $21.7 \%$ and nifedipine $14.3 \%$. Diabetes mellitus was the most common comorbid condition, $35.7 \%$ associated with hypertension, followed by hyperthyroidism $14.5 \%$.

CONCLUSION: This study concluded that by providing insight into the prescription pattern of antihypertensive medication concerning various comorbidities control, it helps the prescriber pay more attention to specific factors that affect the outcome of various comorbidities. 
Keywords: Drug utilization evaluation, Antihypertensives, JNC, Hypertension.

\section{INTRODUCTION}

Drug utilization research is defined as research on "the marketing, distribution, prescription and use of drugs in a society, with special emphasis on the resulting medical, social and economic consequences" and has the principle aim of facilitating drugs' rational use. Drug utilization research developed quickly and soon became the right subject for international congresses in pharmacology and epidemiology. The study aimed to identify the possible association between the increase or decrease in antihypertensive drug groups' utilization. ${ }^{(1)}$

The Seventh Report of the Joint National Committee on the Detection, Evaluation, and Treatment of High Blood Pressure (JNC7) is the most prominent evidence-based clinical guideline in the world for the management of hypertension, supplemented by the 2007 American Heart Association (AHA) Scientific Statement on the treatment of hypertension. ${ }^{(2)}$

It is predominantly an asymptomatic condition, and in more than $95 \%$ of cases, a specific underlying cause of hypertension cannot be found. Many risk factors may contribute to its development, including age, gender weight, physical activity, smoking, family history, serum cholesterol, diabetes mellitus, renal dysfunction, peripheral resistance vessel tone, endothelial dysfunction, autonomic tone, insulin resistance and neurohumoral factors. Hypertension doubles the risk of cardiovascular diseases, including coronary heart disease (CHD), congestive heart failure (CHF), ischemic and hemorrhagic stroke, renal failure, and peripheral arterial disease if not effectively treated. ${ }^{(2)}$

With this projected increase in prevalence rates in Hypertension, the prescription volume of antihypertensive drugs, morbidity and mortality rates are expected to assume an upward trend, especially in India, where healthcare services are sub- optimal for the rapidly expanding populations (Rodgers A et al., 2000). As mentioned earlier, the issues motivated us to undertake the present study, aiming to determine the utilization of antihypertensive drugs in south India. ${ }^{(3)}$

\section{STUDY MATERIALS AND METHODS}

All the relevant and necessary data of the patient were collected from:

- Patient case notes.

- Hospital pharmacy.

- Medication/Treatment chart.

- Prescription. 


\section{Design And Development Of Study Document}

Design of data collection form (DCF):

Suitable data collection form was designed for offline data collection and documentation of all the required data. The developed data collection form consist of details such as patient demographics (Name, age, gender, height, weight, c/o, PMH, provisional diagnosis, current medication, inpatient number, etc.).

\section{Computerization of data collection form}

For easy storage, accessibility, retrieval, and analysis of collected data, online Google forms were designed along with google sheet, online and computerized database was created.

\section{Study procedure:}

This is a prospective observational study; the patients satisfying the inclusion criteria will be enrolled in the study after obtaining their written informed consent. Patient case notes, medication charts, laboratory data and other relevant documents will be reviewed. A suitably designed data collection form will record all the necessary data, including patient demographic details, patient medication history, the reason for admission, any allergic reaction, medication details, and lab investigations.

\section{Data Analysis:}

Data were entered into Google forms, Google sheets and check for accuracy. After that, the data was loaded into SPSS v20 for further analysis. Descriptive statistics on sample characteristics were computed, including means, standard deviation, and frequency of distribution.

\section{Collection of Data:}

Data of patients matching inclusion criteria were recorded. Before including in the study, patients were explained about the aspects of research work. Written informed consent was taken before including him or her into the study. Once the consultation by the physician was over, the prescriptions were copied and patients were interviewed regarding duration of taking antihypertensive drugs and detail of adverse drug reaction if developed. Data like name, age, sex, duration of hypertension, family history, vital data, general examination, laboratory investigation, concurrent diseases, and ongoing treatment was recorded from patient's case.

\section{RESULT AND DISCUSSION}


A total of 322 patients aged between 21-90 years who met the initial inclusion criteria were included in this study.

\begin{tabular}{|c|c|c|}
\hline \multicolumn{3}{|c|}{ Table 1: Categorization of study population based on Gender } \\
\hline Gender & Frequency & Percent \\
\hline Male & 200 & 62.1 \\
\hline Female & 122 & 37.9 \\
\hline Total & 322 & 100.0 \\
\hline
\end{tabular}

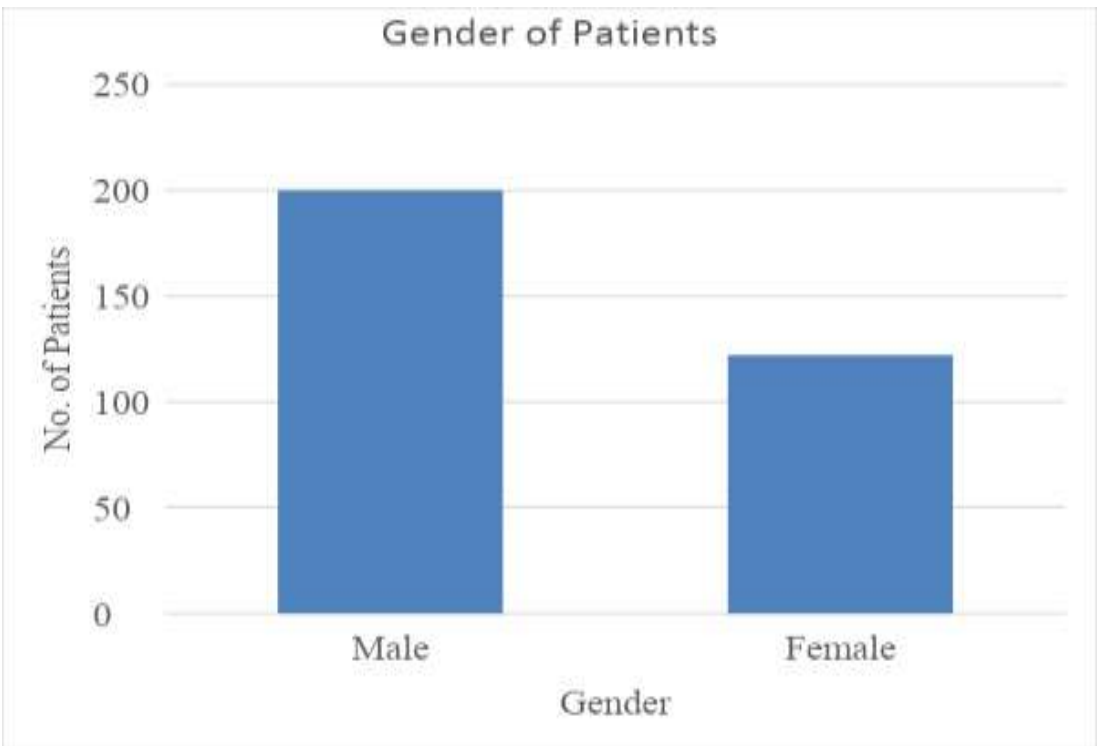

Figure.1 Patients categorization based on gender

As seen from Table (1) and Figure (1), among 322 respondents, 62\% (200) are male and 37.9\% (122) are female. It is clear that number of men is almost double the number of women. Thus, most of patients are male in this survey.

\begin{tabular}{|c|c|c|}
\hline \multicolumn{3}{|c|}{ Table 2: Categorization of hypertensive patients based on age } \\
\hline Age group (Years) & Frequency & Percent \\
\hline $21-30$ & 20 & 6.2 \\
\hline $31-40$ & 39 & 12.1 \\
\hline $41-50$ & 103 & 32.0 \\
\hline $51-60$ & 94 & 29.2 \\
\hline $61-70$ & 55 & 17.1 \\
\hline $71-80$ & 9 & 2.8 \\
\hline$>80$ & 2 & .6 \\
\hline Total & 322 & 100.0 \\
\hline
\end{tabular}




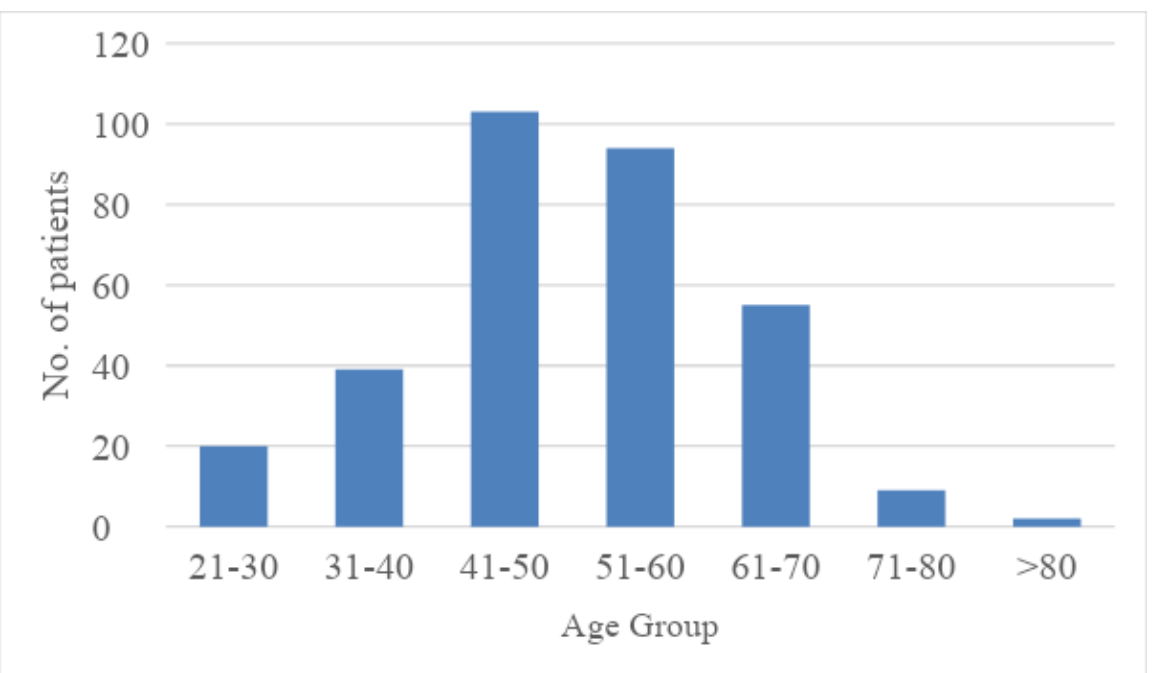

Figure.2 Hypertensive patients' categorization based on age

The study is conducted with 322 respondents in different ages. The researcher divided the respondents into seven age groups from 21 to over 80 years old with each 10 class interval. It is noticed from the Table (2) that people aged from 41-50 is the most dominant with 32\% (103), the highest number recorded while those who are over 71 and under 30 years old are very less around 3.4\% (11) and $6.2 \%$ (20) respectively. The age groups of 31-40 and 51-60 made up for $12.1 \%(39)$ and $17.1 \%(55)$ respectively, followed by the group the group of 51-60 with $29.2 \%$ (94). Hence, it can be said that most of respondents were in the middle age. 


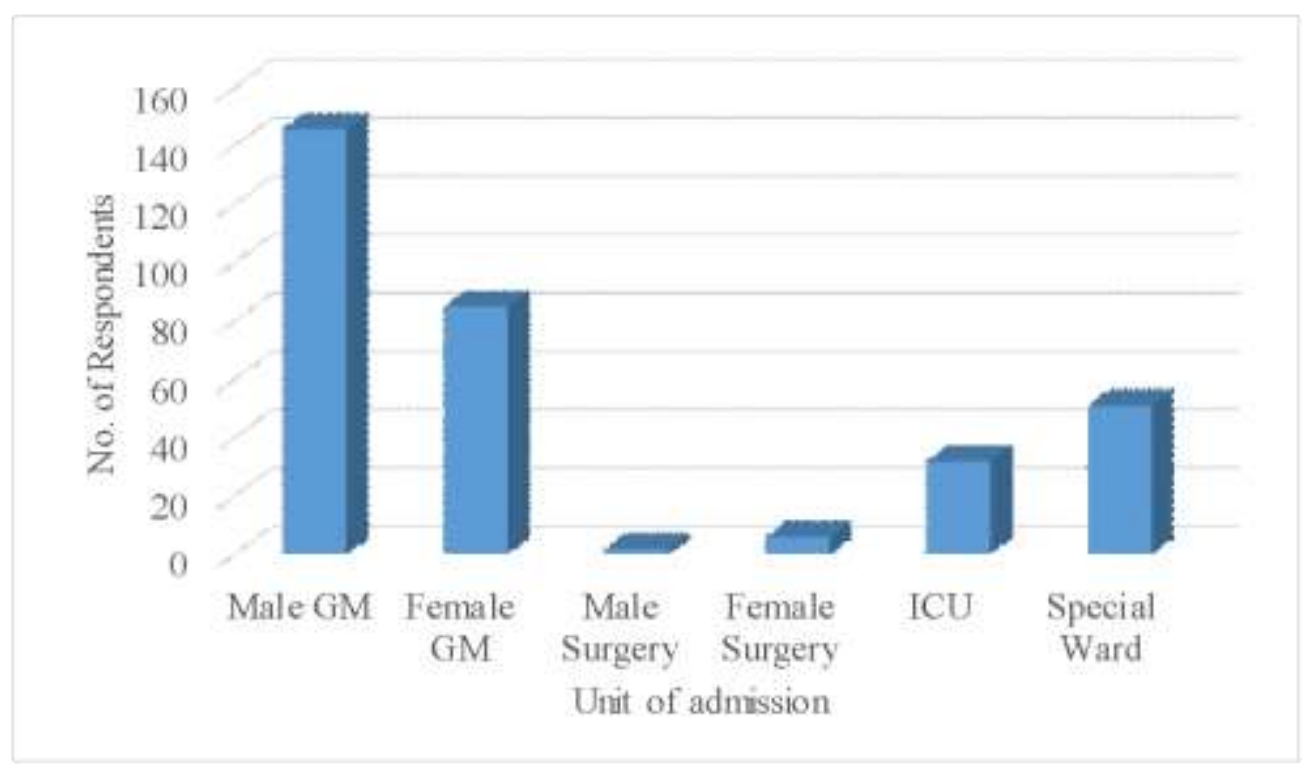

Figure 3: Unit of admission of respondents of the study

Concerning with unit used in hospital, Male GM and Female GM are the most commonly used units with $45.3 \%$ (146) and 26.4\% (85) respectively as seen in Table (3) and Figure (3). By agreement, male surgery and female surgery are less popular with $0.6 \%(2)$ and $1.9 \%$ (6) accordingly. While the number of special ward is $15.8 \%(51)$, the third level in the given data, the figure for ICU is $9.9 \%$ (32). Overall, male GM is dominant.

\begin{tabular}{|c|c|c|}
\hline \multicolumn{3}{|c|}{ Table 4: Past Medical History of respondents of the study } \\
\hline Past Medical History & Frequency & Percent \\
\hline Nil & 90 & 28.0 \\
\hline Hypertension & 125 & 38.8 \\
\hline General & 31 & 9.6 \\
\hline Hypothyroidism & 13 & 4.0 \\
\hline Hyponatremia & 1 & .3 \\
\hline HTN and Hypothyroidism & 5 & 1.6 \\
\hline T2DM,HTN & 37 & 11.5 \\
\hline COPD & 17 & 5.3 \\
\hline TB & 1 & .3 \\
\hline CAD & 2 & .6 \\
\hline Total & 322 & 100.0 \\
\hline
\end{tabular}




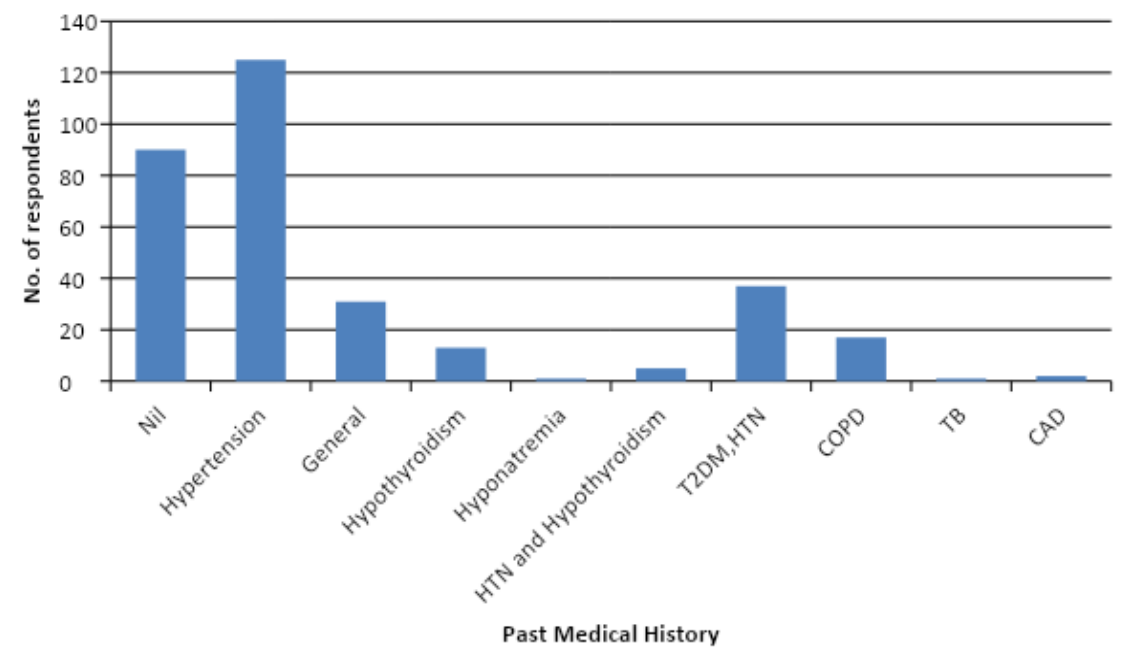

Figure 4: Past Medical History of respondents of the study

The medical history of 322 respondents with more than ten health problems was studied. It's evident from the given result Table(4) that, hypertension is prominent amongst other diseases with 38.8\%(125). It is followed by T2DM, HTN and General problem with $11.5 \%(37)$, and 9.6\% (31) respectively. Interestingly, people with no historical health issues stood at 28\% (90), the second-high number recorded. The other diseases such as COPD, Hypothyroidism, and Hyperthyroidism are less found in these respondents.

\begin{tabular}{|c|c|c|c|}
\hline \multicolumn{4}{|c|}{ Table 5: Demographic data of hypertensive patients based on social habits } \\
\hline Social Habits & Assessment & Frequency & Percent \\
\hline \multirow{2}{*}{ Vegetarian } & Yes & 29 & 9.0 \\
\cline { 2 - 4 } & No & 293 & 91 \\
\hline \multirow{2}{*}{ Smoking } & Yes & 152 & 47.2 \\
\cline { 2 - 4 } & No & 170 & 52.8 \\
\hline \multirow{2}{*}{ Alcoholic } & Yes & 107 & 33.2 \\
\cline { 2 - 4 } & No & 215 & 66.8 \\
\hline \multirow{2}{*}{ Non-Vegetarian } & Yes & 293 & 91 \\
\cline { 2 - 4 } & No & 29 & 9.0 \\
\hline
\end{tabular}




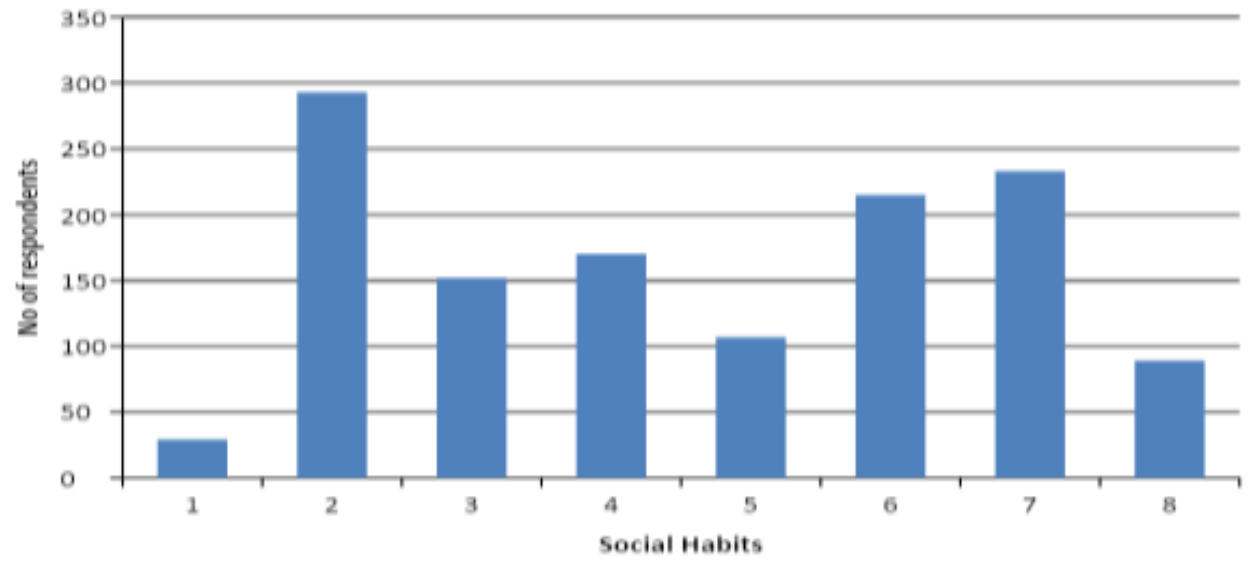

Figure 5: Demographic data of hypertensive patients based on social habits

When 322 people were asked about whether they are vegetarian or non-vegetarians, 91\%(293) of them answered "no" and only small percentage (9\%) (29) for yes. Therefore, most of these patients are non-vegetarians.

In terms of smoking issues, 52.8\%(170) of respondents didn't smoke while 47.2\%(152) smoked. Although the number of non-smoking people are slightly more than the number of smoking ones, the two groups are quite equivalent in number. When 322 people were asked about whether they consumed alcohol or not, 66.8\%(215) of them answered "no" and 33.2\% (107) percentage for yes. Therefore, more than half of these patients did not consume alcohol

\begin{tabular}{|c|c|c|}
\hline \multicolumn{3}{|c|}{ Table 6: Co-Morbidities of the respondents of the study } \\
\hline Co-Morbidities & Frequency & Percent \\
\hline Nil & 68 & 21.1 \\
\hline Hypothyroidism & 25 & 7.8 \\
\hline COPD & 26 & 8.1 \\
\hline Diabetes mellitus & 115 & 35.7 \\
\hline Hyperthyroidism & 48 & 14.9 \\
\hline TB & 8 & 2.5 \\
\hline Coronary Artery disease & 25 & 7.8 \\
\hline Diabetes mellitus, Hypothyroidism & 1 & .3 \\
\hline Diabetes mellitus, Coronary Artery disease & 1 & .3 \\
\hline Diabetes mellitus, TB & 1 & .3 \\
\hline Hypothyroidism, COPD & 1 & .3 \\
\hline Diabetes mellitus, COPD & 2 & .6 \\
\hline
\end{tabular}




\begin{tabular}{|c|c|c|}
\hline Hypothyroidism, Coronary Artery disease & 1 & .3 \\
\hline Total & 322 & 100.0 \\
\hline
\end{tabular}

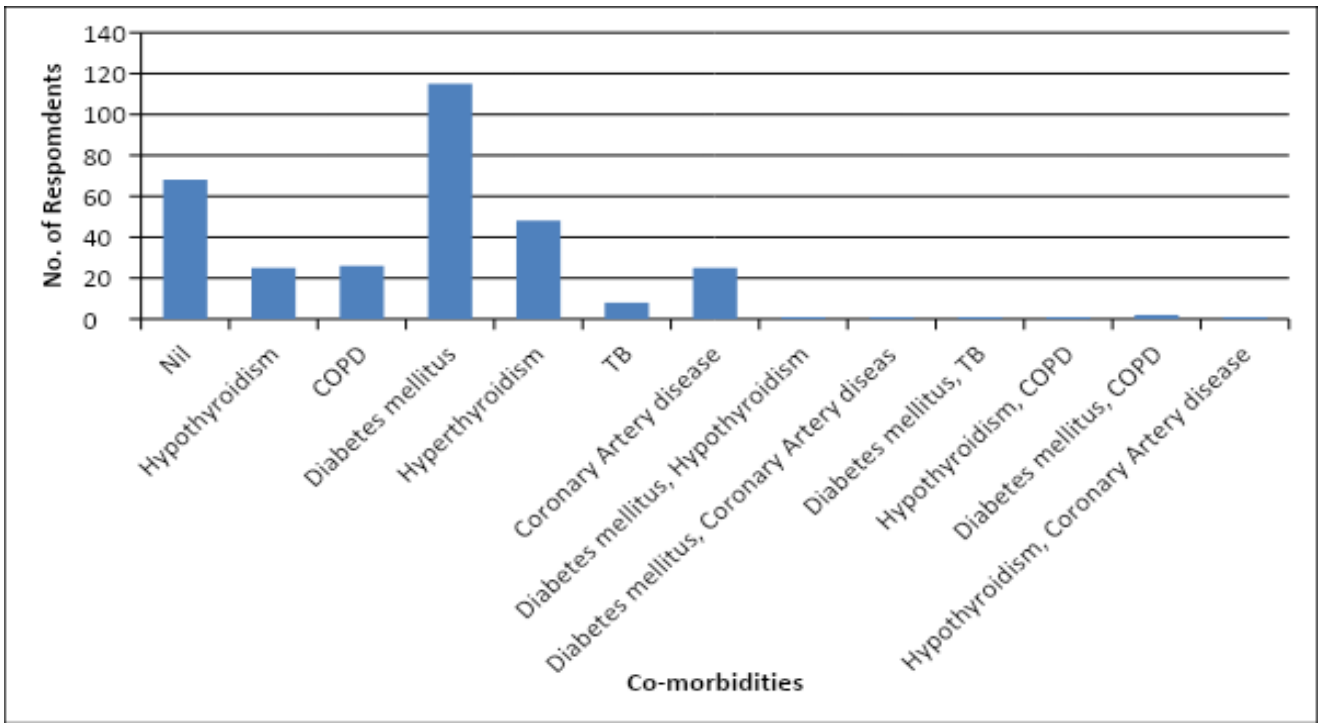

Figure 6: Co-Morbidities of the respondents of the study

To continue the study, the researcher listed out a wide variety of diseases which are likely to accompany with Hypertension. It can be seen from the Table (6) that Diabetes mellitus occurred most frequently at $35.7 \%$ (115) and it is followed by "no previous history" at $21.1 \%$ (68). Hypothyroidism, COPD and Coronary Artery diseases are less prominent with Hypertension, standing at $8 \%$ approximately. The other diseases such as Diabetes mellitus, Hypothyroidism, Diabetes mellitus, TB and Hypothyroidism, Coronary Artery have less chance to come with the original disease at very small portions (less than $1 \%$ ).

\begin{tabular}{|c|c|c|}
\hline \multicolumn{3}{|c|}{ Table 7: Anti-Hypertensive Class of the respondents of the study } \\
\hline Anti-Hypertensive Class & Frequency & Percent \\
\hline ACE inhibitors & 100 & 31.1 \\
\hline Diuretics & 50 & 15.5 \\
\hline Ca channel blockers (CCBs) & 69 & 21.4 \\
\hline Combinations Therapy & 18 & 5.6 \\
\hline ACE inhibitors & 22 & 6.8 \\
\hline Beta blockers & 44 & 13.7 \\
\hline Angiotensin Receptor Blockers & 19 & 5.9 \\
\hline Total & 322 & 100.0 \\
\hline
\end{tabular}




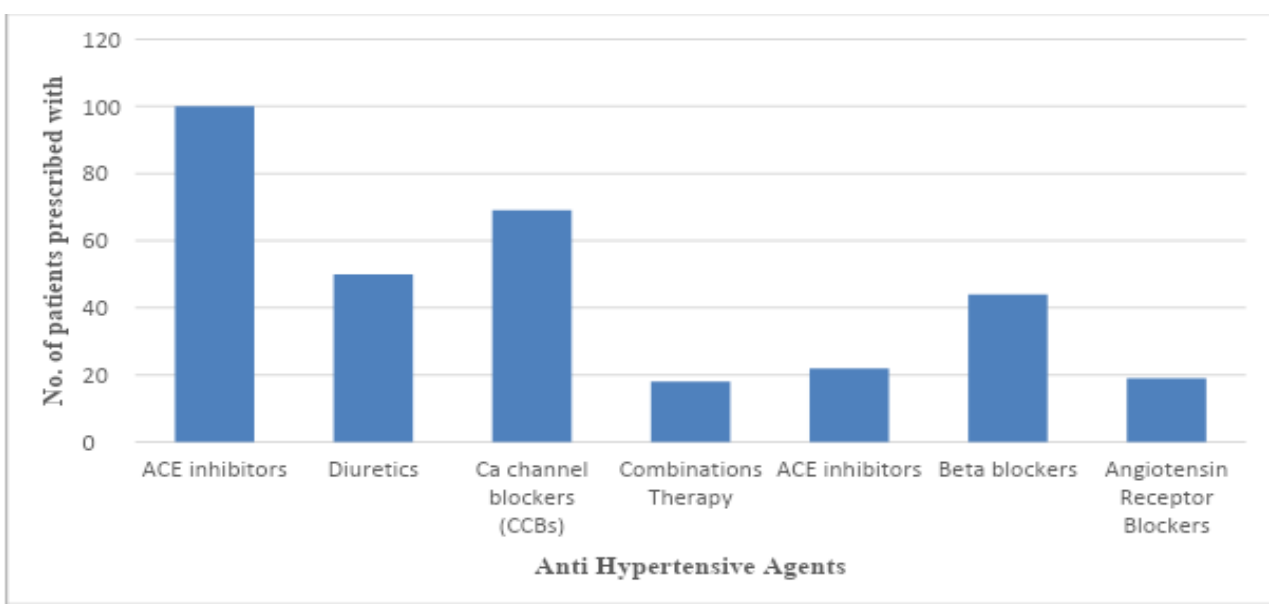

Figure 7: Anti-Hypertensive Class of the respondents of the study

The wide variety of first-line agents available for managing high blood pressure include Diuretics, Beta Adrenergic Receptor Blockers, Alpha Adrenergic Receptor Blockers, Angiotensin Converting Enzyme inhibitors, and Calcium Channel blockers. From the table, ACE inhibitor is the most common used for Hypertension treatment with $31.1 \%$ (100). Similarly, Ca channel blocker (CCBs) is also used frequently but in smaller level 21.4\% (69). While Diuretics and Beta blockers are applied in quite equivalent frequencies at 15.5(50) and 13.7 (44) respectively, combinations Therapy, ACE inhibitors Angiotensin Receptor Blockers are three drugs less utilized for Hypertensive patients compared to others.

\begin{tabular}{|c|c|c|}
\hline \multicolumn{3}{|c|}{ Table 8: Angiotensin Receptor Blockers used by respondents of the study } \\
\hline Angiotensin Receptor Blockers & Frequency & Percent \\
\hline Non & 303 & 94.1 \\
\hline Telmisartan & 12 & 3.7 \\
\hline Olmesartan & 4 & 1.2 \\
\hline Losartan & 3 & .9 \\
\hline Total & 322 & 100.0 \\
\hline
\end{tabular}




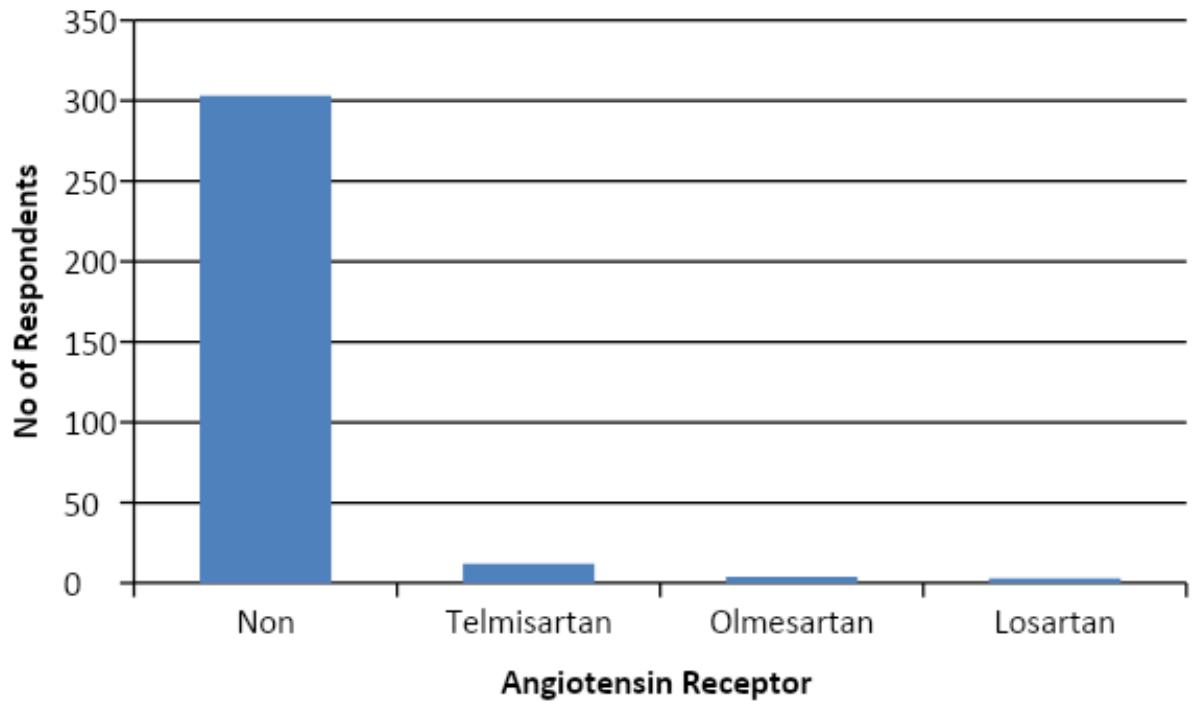

Figure 8: Angiotensin Receptor Blockers used by respondents of the study

As regards to Angiotensin_receptor_blockers, it is found under many brand names. However, as seen in Table (8) most of the respondents did not use blockers of any kind. The three names Telmisartan, Olmesartan and Losartan are less popular in the market and hence hardly used.

\begin{tabular}{|c|c|c|}
\hline \multicolumn{2}{|c|}{ Table 9: ACE inhibitors used by the respondents of the study } \\
\hline ACE inhibitors & Frequency & Percent \\
\hline Non & 200 & 62.1 \\
\hline Captopril & 70 & 21.7 \\
\hline Enalapril & 22 & 6.8 \\
\hline Ramipril & 30 & 9.3 \\
\hline Total & 322 & 100.0 \\
\hline
\end{tabular}

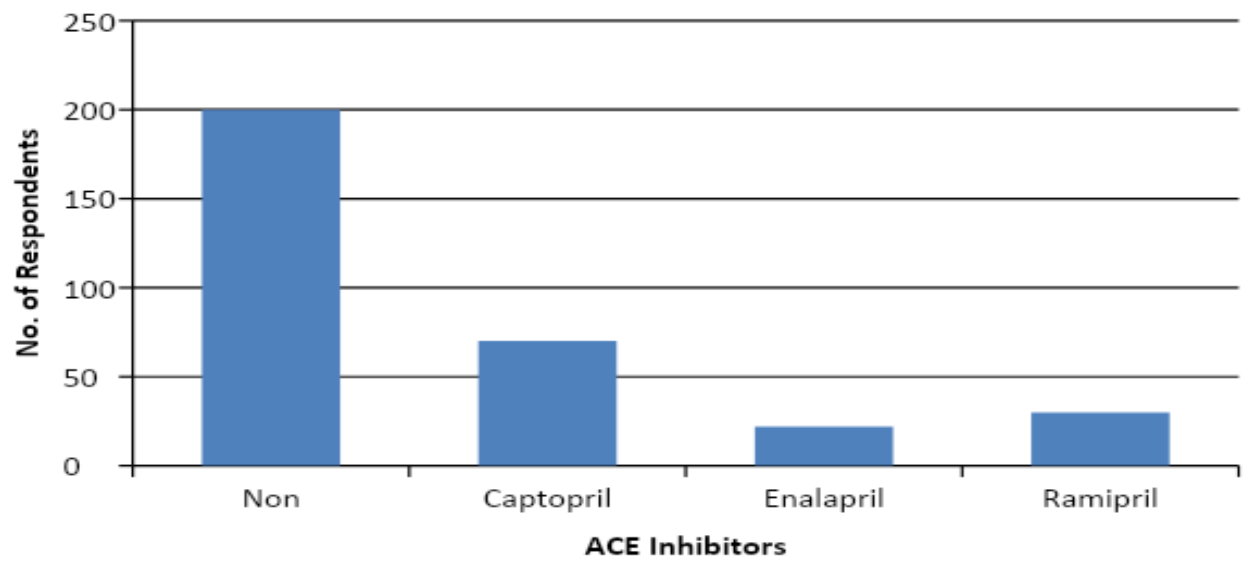

Figure 9: ACE inhibitors used by the respondents of the study 
With regard to ACE_Inhibitors, 62\% (200) a majority of the respondents did not use any kind of inhibitors. Sometimes people also use it under name Captopril 21\% (70). Enalapril and Ramipril are not popularized in comparison with other names.

\begin{tabular}{|c|c|c|}
\hline \multicolumn{3}{|c|}{ Table 10: Beta Blockers used by the respondents of the study } \\
\hline Beta Blockers & Frequency & Percent \\
\hline Non & 278 & 86.3 \\
\hline Propronalol & 9 & 2.8 \\
\hline Atenolol & 35 & 10.9 \\
\hline Total & 322 & 100.0 \\
\hline
\end{tabular}

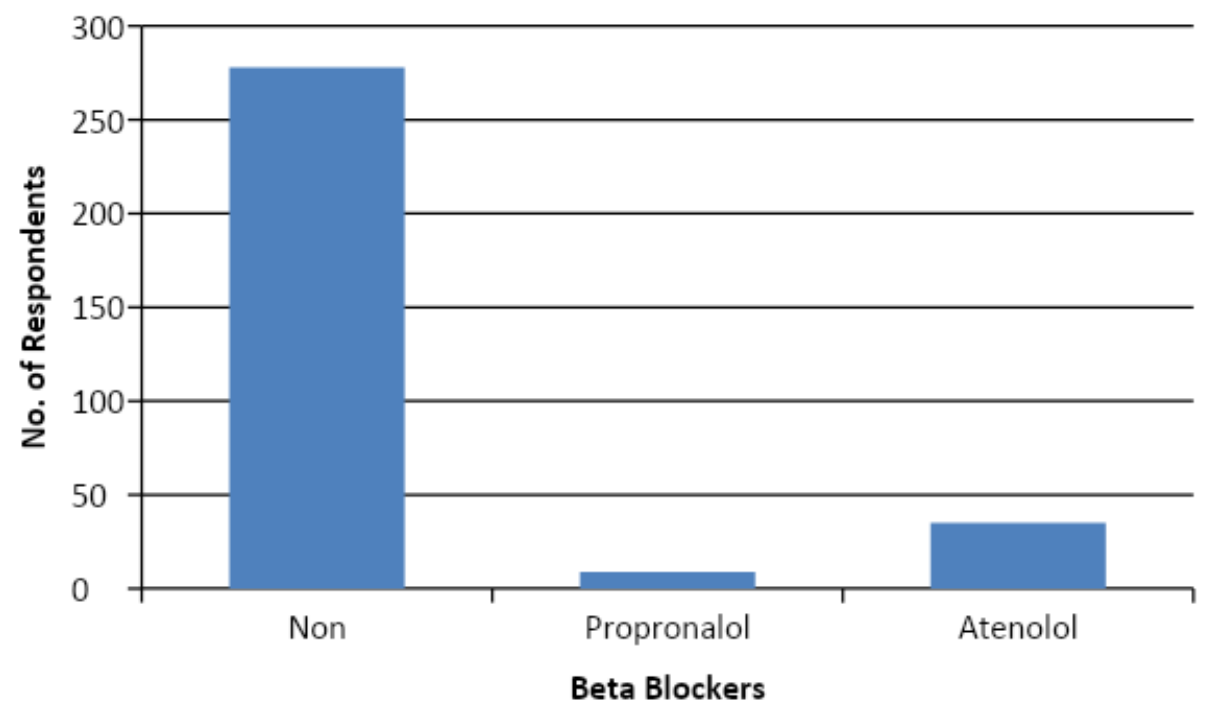

Figure 10: Beta Blockers used by the respondents of the study

When it comes to Beta blockers, most of the respondents $278(86.3 \%)$ did not use any Beta Blocker. Atenolol and Propronalol used are not prominent. However, compared to Propronalol, Atenlol is still taken more regularly.

\begin{tabular}{|c|c|c|}
\hline \multicolumn{2}{|c|}{ Table 11: $\mathbf{C a}^{+}$Channel_Blockers used by the respondents of the study } \\
\hline $\mathbf{C a}^{+}$Channel_Blockers & Frequency & Percent \\
\hline Non & 253 & 78.6 \\
\hline Amlodipine & 23 & 7.1 \\
\hline Nefidipine & 46 & 14.3 \\
\hline Total & 322 & 100.0 \\
\hline
\end{tabular}




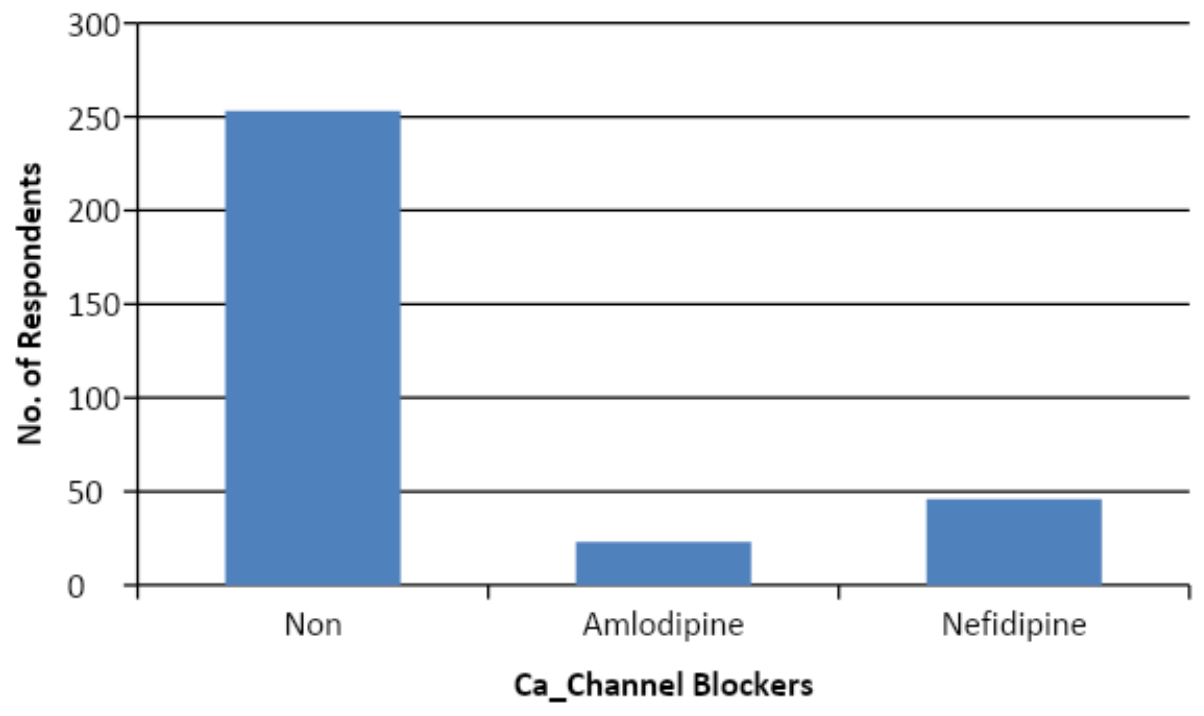

Figure 11: Ca_Channel_Blockers used by the respondents of the study

Regarding to $\mathbf{C a}^{+}$Channel_Blockers, most people 253(78.6\%) did not use any of these blockers. Although Nefidipine and Amlodipine are less common, Nefidipine is more prominent than Amlodipine with the doubled percentage recorded.

\begin{tabular}{|c|c|c|}
\hline \multicolumn{3}{|c|}{ Table 12: Diuretic used by the respondents of the study } \\
\hline Diuretic & Frequency & Percent \\
\hline Non & 272 & 84.5 \\
\hline Hydrochlorothiazide & 12 & 3.7 \\
\hline Furosemide & 35 & 10.9 \\
\hline Mannitol & 3 & .9 \\
\hline Total & 322 & 100.0 \\
\hline
\end{tabular}

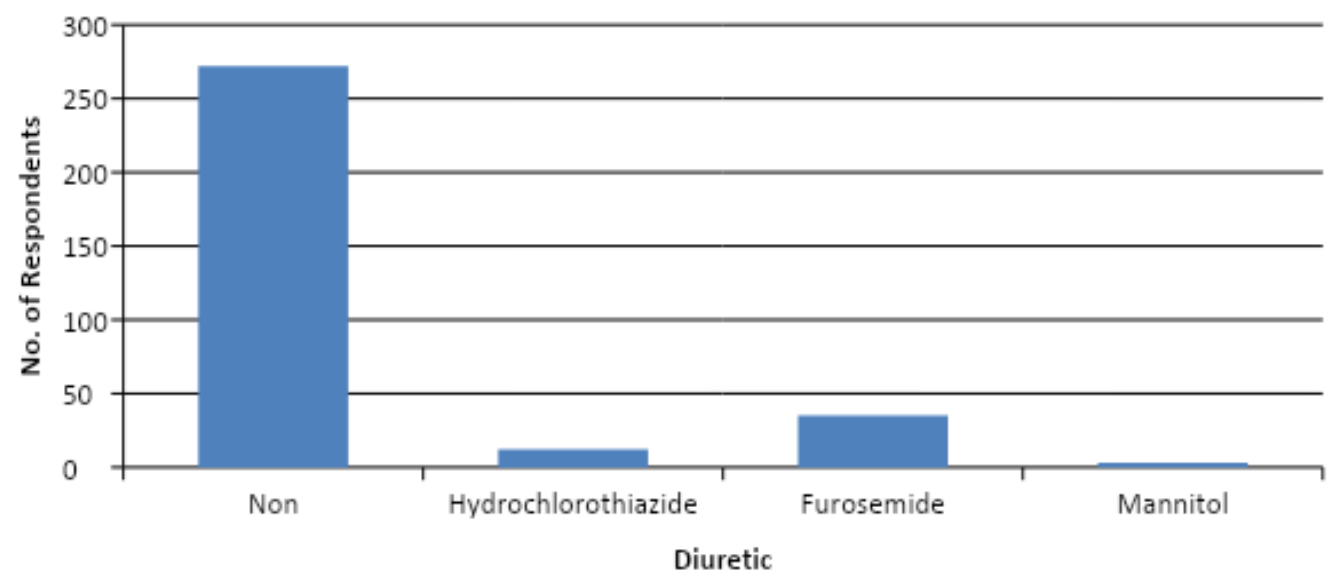

Figure 12: Diuretic used by the respondents of the study 
Concerning about Diuretic, most respondents 84.6\% (272) did not use diuretic of any type. while Furosemide, Hydrochlorothiazide and Mannitol are less used in this field. It is also noted that Furosemide is still known with $10.9 \%$ meanwhile Mannitol is rarely utilized with less than $1 \%$.

\begin{tabular}{|c|c|c|}
\hline \multicolumn{3}{|c|}{ Table 13: Combination Therapy used by the respondents of the study } \\
\hline Combination Therapy & Frequency & Percent \\
\hline Non & 304 & 94.4 \\
\hline CCB + B-Blockers & 9 & 2.8 \\
\hline ACE + Diuretics & 3 & .9 \\
\hline CCB + Diuretics & 6 & 1.9 \\
\hline Total & 322 & 100.0 \\
\hline
\end{tabular}

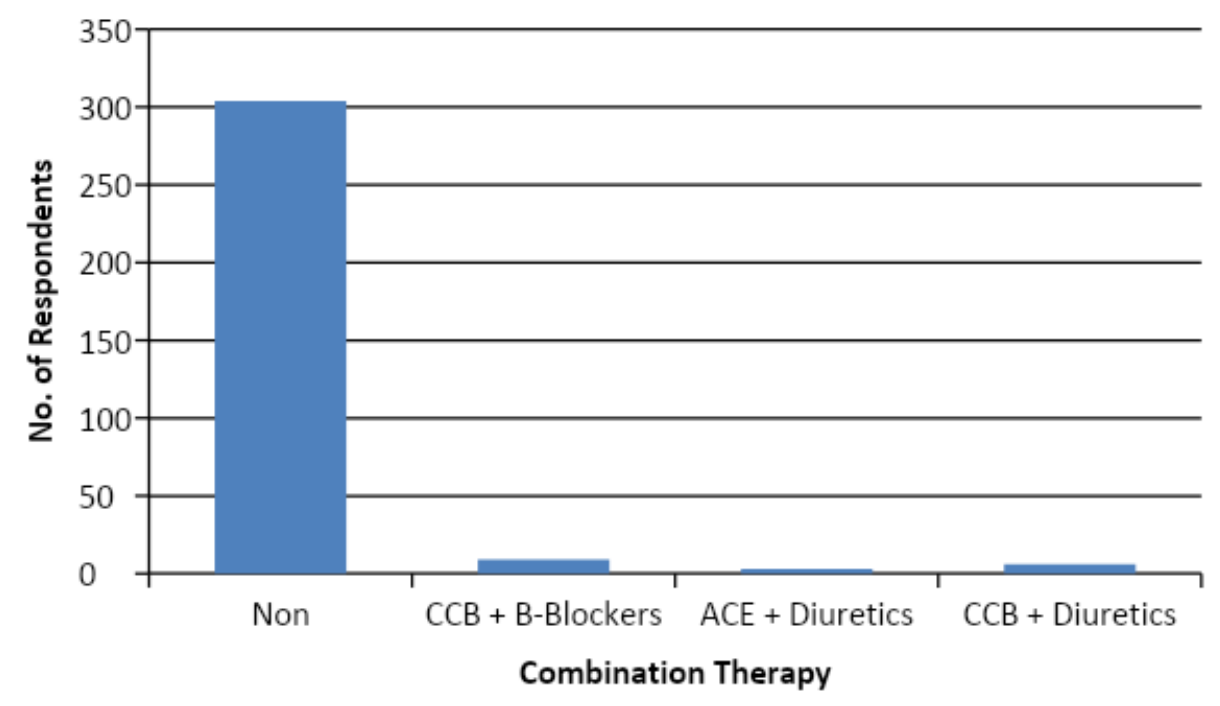

Figure 13: Combination Therapy used by the respondents of the study

In terms of combination therapy methods, most respondents (94.4\%) did not use any combination of the blockers. Other methods like $\mathrm{CCB}+\mathrm{B}$-Blockers $\mathrm{CCB}+\mathrm{B}$-Blockers and $\mathrm{CCB}+$ Diuretics are less used. 


\begin{tabular}{|c|c|c|}
\hline Blood Pressure & Frequency & Percent \\
\hline $100 / 80$ & 1 & .3 \\
\hline $110 / 70$ & 1 & .3 \\
\hline $110 / 80$ & 1 & .3 \\
\hline $120 / 70$ & 2 & .6 \\
\hline $120 / 80$ & 20 & 6.2 \\
\hline $120 / 90$ & 10 & 3.1 \\
\hline $130 / 70$ & 2 & .6 \\
\hline $130 / 80$ & 15 & 4.7 \\
\hline $130 / 90$ & 39 & 12.1 \\
\hline $130 / 100$ & 4 & 1.2 \\
\hline $140 / 80$ & 4 & 1.2 \\
\hline $140 / 90$ & 96 & 29.8 \\
\hline $140 / 100$ & 20 & 6.2 \\
\hline $140 / 110$ & 5 & 1.6 \\
\hline $150 / 80$ & 1 & .3 \\
\hline $150 / 90$ & 23 & 7.1 \\
\hline $150 / 100$ & 14 & 4.3 \\
\hline $150 / 110$ & 5 & 1.6 \\
\hline $160 / 90$ & 5 & 1.6 \\
\hline $160 / 100$ & 8 & 2.5 \\
\hline $160 / 110$ & 39 & 12.1 \\
\hline $170 / 100$ & 5 & 1.6 \\
\hline $170 / 110$ & 2 & .6 \\
\hline Total & 322 & 100.0 \\
\hline
\end{tabular}

Ideal blood pressure is considered to be between $90 / 60 \mathrm{mmHg}$ and $120 / 80 \mathrm{mmHg}$. high blood pressure is considered to be $140 / 90 \mathrm{mmHg}$ or higher. low blood pressure is considered to be 90/60mmHg or lower.

As can be seen from the above Table (14) majority of the respondents had high blood pressure ranging from $120 / 90$ to $17 / 110$. Only in $1 \%$ of the respondents the blood pressure was to be normal. 


\begin{tabular}{|c|c|c|}
\hline \multicolumn{3}{|c|}{ Table 15: Pulse Rate of the respondents of the study } \\
\hline Pulse Rate & Frequency & Percent \\
\hline$<70$ & 3 & .9 \\
\hline $70-80$ & 58 & 18.0 \\
\hline $80-90$ & 60 & 18.6 \\
\hline $90-100$ & 183 & 56.8 \\
\hline $100-110$ & 2 & .6 \\
\hline $110-120$ & 3 & .9 \\
\hline$>120$ & 13 & 4.0 \\
\hline Total & 322 & 100.0 \\
\hline
\end{tabular}

A normal resting heart rate for adult's ranges from 60 to 100 beats per minute. Generally, a lower heart rate at rest implies more efficient heart function and better cardiovascular fitness. As seen from the above Table (15) more than $90 \%$ of the respondents had a normal heart rate.

\begin{tabular}{|c|c|c|}
\hline \multicolumn{3}{|c|}{ Table 16: Body Temperature of the respondents of the study } \\
\hline Temperature & Frequency & Percent \\
\hline 31 & 1 & .3 \\
\hline 33 & 1 & .3 \\
\hline 36 & 10 & 3.1 \\
\hline 37 & 240 & 74.5 \\
\hline 38 & 43 & 13.4 \\
\hline 39 & 21 & 6.5 \\
\hline 40 & 3 & .9 \\
\hline 41 & 2 & .6 \\
\hline 42 & 1 & .3 \\
\hline Total & 322 & 100.0 \\
\hline
\end{tabular}

Normal body temperatures vary depending on many factors, including a person's age, sex, and activity levels. The normal body temperature for an adult is around $98.6^{\circ} \mathrm{F}\left(37^{\circ} \mathrm{C}\right)$, but every person's baseline body temperature is slightly different, and may consistently be a little higher or lower. As seen from the above Table (16) majority of the respondents had a normal temperature. However, $13.4 \%$ had fever, $6.5 \%$ high fever and $1.8 \%$ very high fever. 


\begin{tabular}{|c|c|c|}
\hline \multicolumn{3}{|c|}{ Table 17: JNC7 of the respondents of the stud } \\
\hline JNC7 & Frequency & Percent \\
\hline Stage 1(140-159/90-99) & 166 & 51.6 \\
\hline Pre-Hypertension(120-139/80-89) & 96 & 29.8 \\
\hline Stage 2(>160/>100) & 60 & 18.6 \\
\hline Total & 322 & 100.0 \\
\hline & & \\
\hline
\end{tabular}

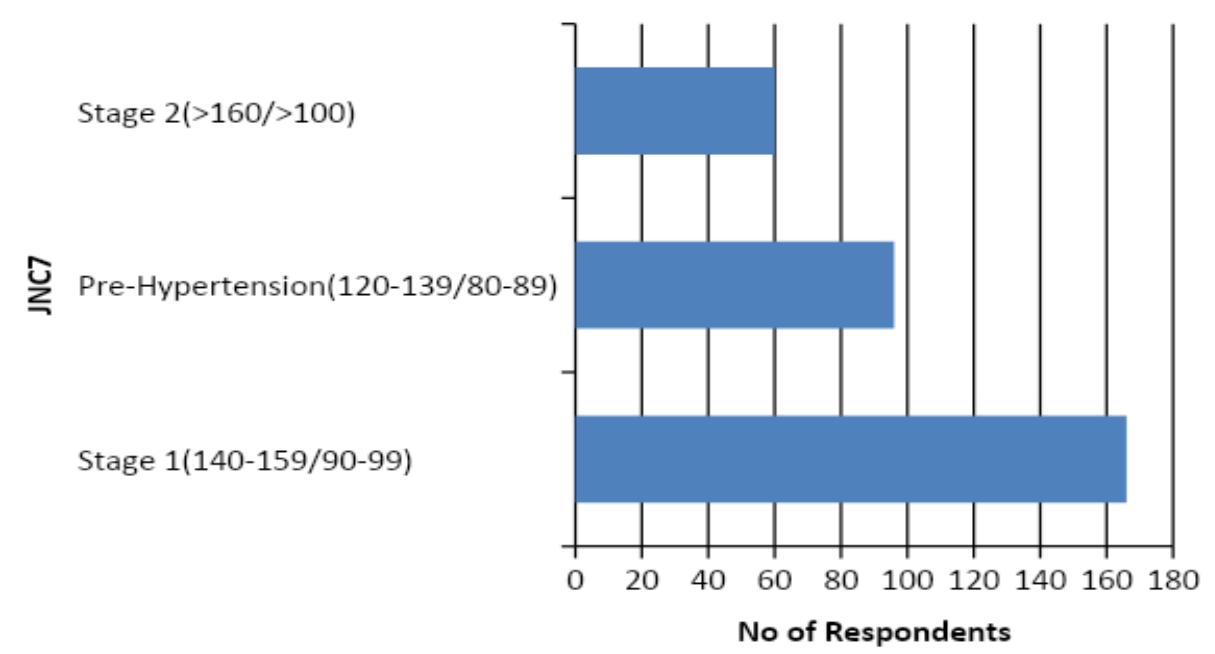

Figure 14: JNC7 of the respondents of the study

JNC 7 suggests that all people with hypertension (stages 1 and 2) be treated. The treatment goal for individuals with hypertension and no other compelling conditions is $<140 / 90 \mathrm{mmHg}$. According to the table (17), most of patients are in stage of level 1 with $51.6 \%$ and Stage 2 is $18.6 \%$ and pre-hypertension is $29.8 \%$

\begin{tabular}{|c|c|c|}
\hline \multicolumn{3}{|c|}{ Table 18: Cost of Drug used by the respondents of the study } \\
\hline Cost of Drug & Frequency & Percent \\
\hline Rs.0-Rs.50 & 273 & 84.8 \\
\hline Rs.51-Rs.100 & 32 & 9.9 \\
\hline Rs.101-Rs.150 & 17 & 5.3 \\
\hline Total & 322 & 100.0 \\
\hline
\end{tabular}




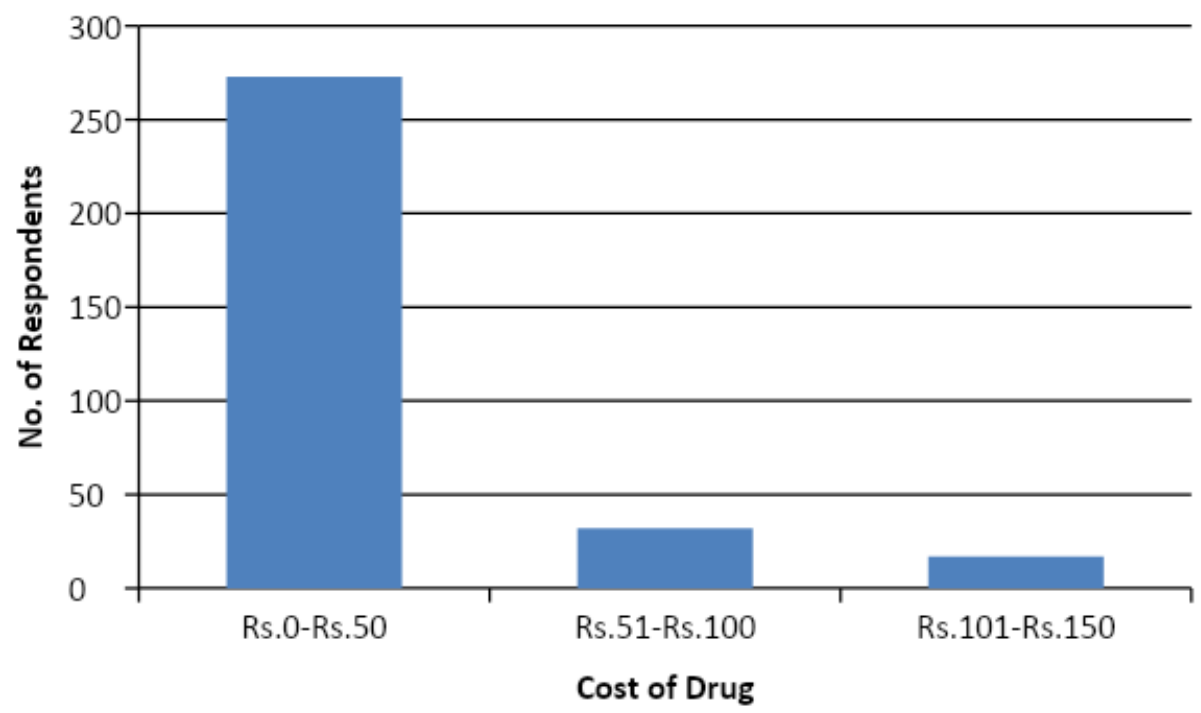

Figure 15: Cost of Drug used by the respondents of the study

While diuretics cost between 6 cents and 10 cents a day, it costs about $\$ 1.60$ daily for a betablocker (another drug used to treat high blood pressure) and \$1.46 for an ACE inhibitor. As can be seen from the above table (18) majority of the respondents of the study were on low cost diuretics which costed less than Rs.50 About 5.3\% of the respondents were on beta blockers whose cost ranged from Rs.101 to Rs.150 . 9.9\% were on ACE inhibitor which were priced in between Rs.51 to Rs. 100 


\section{Discussion:}

The study result reveals that the rate of hypertension in male patients $200(62.1 \%)$ was higher than that of female population 122(37.9\%) [Table No.1]. This is inline by similar study conducted by Vikas Pandey et al (2014) [1] which also reported the proportion of males was on the higher side as compared with females.

The age categorization of the patients was analyzed. Majority of the patients were in the age group of 40-70 years of age 252 (78.3\%). [Table No:2]. A similar study conducted by Popuri Rupa Sindhu et al (2013) [2] also reported that prevalence rates of hypertension among the people above 50 years of age were high.It was see that Male GM and Female GM are the most commonly used units with $45.3 \%$ (146) and 26.4\% (85) respectively as seen in [Table No.3]. By agreement, male surgery and female surgery are less popular with $0.6 \%(2)$ and $1.9 \%$ (6) accordingly. While the number of special ward is $15.8 \%$ (51), the third level in the given data, the figure for ICU is $9.9 \%$ (32).

In all ten health problems was studied. Table No. 4 shows that, hypertension is prominent amongst

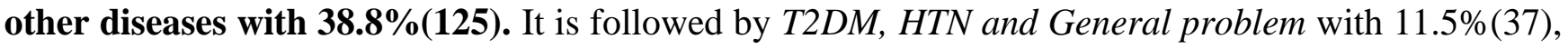
and $9.6 \%$ (31) respectively. The other diseases such as COPD, Hypothyroidism, and Hyperthyroidism are less found in these respondents.

The social history of the respondents of study revealed that most of the respondents $91 \%(293)$ were Non-vegetarians, 47.2\%(152) were habituated to smoking and 33.2\% (107) consumed alcohol as was seen in Table No. 5. A similar study conducted by Arshad H Mohad et al (2012) [3] reported that the prevalence of hypertension risk factors in the general population in which smoking were observed.The co-morbidity of the hypertensive patients was analysed. The study reveals that majority of the study population were suffering from diabetes mellitus 115(35.7\%) [Table No: 6]. A similar study conducted by Giri D Rajasekhar et al (2015) [4] also reported that most common comorbid condition among hypertensive population was diabetes mellitus. This report correlates with the current study result. In this present study, ACE inhibitors 100(31.1\%), Calcium channel blocker 69 (21.4\%) and Beta Blockers $44(13.7 \%)$ were the most commonly prescribed antihypertensive agents [Table No: 7]. A similar study done by Rachana PR et al (2014) [5] reported calcium channel blocker (41.97\%) were most frequently used class of antihypertensive drugs. Angiotensin_receptor_blockers is found under many brand names. However, as seen in Table No. [8] most of the respondents did not use blockers of any kind. The three names Telmisartan, Olmesartan and Losartan are less popular in the market and hence hardly used. With regard to ACE_Inhibitors, 62\% (200) a majority of the respondents did not use any kind of inhibitors. Sometimes people also use it under name Captopril 21\% (70) as seen in Table No. [9]. Enalapril and Ramipril are not popularized in comparison with other names. Most of the respondents 278 (86.3\%) did not use any Beta Blocker. Atenolol and Propronalol used are not prominent. However, compared to Propronalol, Atenlol is still taken more regularly Table No. [10]. Ca_Channel_Blockers was not used by most people 253(78.6\%) as seen in Table No. [11]. Although Nefidipine and Amlodipine are less common, Nefidipine is more prominent than Amlodipine with the doubled percentage recorded.Most respondents 84.6\% (272) did not use Diuretic of any type Table No. [12]. Furosemide, Hydrochlorothiazide and Mannitol are less used in this field. It is also noted that Furosemide is still known with $10.9 \%$ meanwhile Mannitol is rarely utilized with less than 
1\%.Combination therapy methods was not used by most respondents (94.4\%) Table No. [13]. Combinations like CCB + B-Blockers CCB + B-Blockers and CCB + Diuretics were rarely used.

As seen from Table No. [14] majority of the respondents had high blood pressure ranging from 120/90 to $17 / 110$. Only in $1 \%$ of the respondents the blood pressure was to be normal. But the heart rate was normal in most patients $90 \%$ as can be seen from Table No. [15]. Table No. [16] shows that majority of the respondents had a normal temperature. However, $13.4 \%$ had fever, $6.5 \%$ high fever and $1.8 \%$ very high fever.

The categorization of patients depending on the JNC 7 classification revealed that more number of patients $166(51.6 \%)$ were in Stage 1 hypertension [Table No: 17]. A similar study conducted by Manasa Cidda et al (2014) [6] revealed that most of the patients were under the category of stage 1 hypertension 204(56.7\%).

As seen from the Table N0. [18] majority of the respondents of the study were on low cost diuretics which costed less than Rs.50 About 5.3\% of the respondents were on beta blockers whose cost ranged from Rs.101 to Rs.150 . 9.9\% were on ACE inhibitors which were priced in between Rs.51 to Rs.100.

\section{Conclusion:}

Through the current study, the drug utilization pattern of antihypertensive in general medicine department could be assessed. This study has provided an insight into the prescription patterns of antihypertensive medications with respect to various co-morbidities control. It will help prescribers to pay more attention for specific factors that affect outcome of various co-morbidities. Studies from every now and then are required in drug utilization pattern and standard treatment guidelines to be circulated among prescribing clinicians. There is need of creating awareness about current management of hypertension to clinicians by organizing various workshops. Therefore, educational strategies must be carried out to focus on utilization of antihypertensive medications and overcoming individual risk factor. Also raising patient trust in the physicians, the physicians may improve patient motivation to take prescribed medication.

The trend of hypertension is on the rise, if treated rationally this disease can be overcome. Patients too need to express their interest to know more about the drugs they have been prescribed, and this can promote a safe knowledge on their illness and special care, which would improve their quality of life.

\section{Reference:}

1. KH, U., S, R., E, V. And Y, P., 2013. Drug Use Evaluation Of Antihypertensive Medications In Out Patients Ina Secondary Care Hospital. Asian Journal Of Pharmaceutical And Clinical Research,2013;6(2).

2. Surapaneni S, Arifa S, Venigalla S, PL H, Pingili R, Challa S. An Assessment of Antihypertensive Drug Utilization Patterns and Adherence to JNC-7 Guidelines in South Indian Tertiary Care Teaching Hospital. Indian Journal of Pharmacy Practice. 2015;8(4):177-182. 
3. Babu R H, Reddy M M, S V. Drug Utilisation Study of Antihypertensive Agents in an Urban Primary Health care Centre in South India. International Journal of Innovative Pharmaceutical Research. 2012;3(3):244-246.

4. Solanki K, Mistry R, Singh A, Jadav S, Patel N, Trivedi H. Drug utilization study of antihypertensive drugs and their adverse effects in patients of a tertiary care hospital. Journal of Clinical \& Experimental Research. 2013;1(3):58.

5. Philip R, A. D, Mathew M, Tanuja Reddy V1, M. M, Krishnamurthy M. 2016. Prescribing Patterns Of Antihypertensive Drugs In Geriatric Population In Tertiary Care Hospital. IJPR 6(3): 114-9.

6. Ibrahim Abdullah Maghrabi. 2013. Evaluation Of Antihypertensive Prescribing Pattern In The Western Region Of Saudi Arabia And Its Compliance With National Guidelines. Saudi J Health Sci 2(2):118-126.

7. Karras D, Kruus L, Cienki J, Wald M, Chiang W, Shayne P et al. Evaluation and Treatment of Patients With Severely Elevated Blood Pressure in Academic Emergency Departments: A Multicenter Study. Annals of Emergency Medicine. 2006;47(3):230-236.

8. Bhavika D, Prasanna V, Swathi B. Drug utilization study of antihypertensive drugs in a tertiary care hospital. International Journal of Basic and Clinical Pharmacology. 2016;:1580-1585.

9. Altaf M, Rasheed A, Mujtaba A, Mohammed S. Drug Utilisation Evaluation Of Antihypertensives In Geriatric Patients In A Tertiary Care Teaching Hospital. International Journal of Pharmacy and Pharmaceutical sciences. 2014;6(9).

10. Kaura S, Gupta S, Khajuria V, Sharma A, Gupta R, Gupta S. Prescribing Pattern Of Antihypertensive Drugs In A Tertiary Care Hospital Of Northern India. IJPBS. 2013;3(2):304308.

11. Vikas Pandey, Ubedul Hoda, M. Aqil, M. Sharma, M. Akhtar, R. Khandelwal, Abul Kalam Najmi. Evaluation of prescribing patterns in diabetic and hypertensive patients in a South Delhi hospital. International Journal of Basic \& Clinical Pharmacology; 2014; 3 (3):490-495.

12. Popuri Rupa Sindhu, Malladi Srinivas Reddy. Study of Prescriptive Patterns of Antihypertensive Drugs in South India. International Journal of Advancements in Research \&Technology; 2013; 2( 6):295-311.

13. Arshad H Mohd, Uday V Mateti, Venkateswarlu Konuru, Mihir Y Parmar, Buchi R Kunduru. A study on prescribing patterns of antihypertensives in geriatric patients. Perspectives in Clinical Research;2012;3(4):139-142.

14. D.Giri Rajasekhar, D.Guru Prasanna, P.Chandrakanth. Prescribing pattern of antihypertensive drugs based on compelling indications with hypertension. International Journal of Pharmacy and Pharmaceutical Sciences;2016; 8(2): 72-75.

15. Rachana P R, Anuradha H V, Shivamurthy M C. Anti-Hypertensive Prescribing Patterns and Cost Analysis for Primary Hypertension: a retrospective study. Journal of Clinical and Diagnostic Research; 2014;8(9)19- 22.

16. Manasa Cidda, Uday Venkat Mateti, Murali Krishna Batchu, Srinivas Martha. Study of prescribing patterns of antihypertensives in the South Indian population. International Journal of Basic \& Clinical Pharmacology;2014; 3(2): 303-307. 